\title{
Deep Cryogenic Treatment: A Bibliographic Review
}

\author{
P. Baldissera ${ }^{*}$ and C. Delprete
}

Politecnico di Torino - Dipartimento di Meccanica, Corso Duca degli Abruzzi 24, 10129 Torino, Italy

\begin{abstract}
The use of cryogenic treatment (CT) to improve mechanical properties of materials has been developed from the end of the Sixties. At the present time, the initial mistrust about CT has been cleared up and many papers about different materials reporting laboratory tests results, microstructural investigations and hypothesis on CT strengthening mechanisms have been published. The removal of retained austenite combined with fine dispersed $\eta$-carbides precipitation have been widely observed and their effects on mechanical properties have been measured. In addition, some recent studies have pointed out a different mechanism for fatigue strengthening of stainless steels, which involves nano-martensite formation during the CT. The present paper summarizes the state of art about CT, focusing on methods, parameters, results and assumed microstructural mechanisms, in order to get a starting point for new researches to come.
\end{abstract}

\section{INTRODUCTION}

The use of thermal treatments to improve mechanical properties of metal components is an ancient art expanded down the ages until today. Many of the developed processes apply treatments in a range of temperature higher than room temperature. The first attempts to perform subzero treatments were investigated at the beginning of the $20^{\text {th }}$ century, but the actual interest on cryogenic treatment (or cryotreatment, CT) was developed during the last years of the century.

The basic CT consists in a gradual cooling of the component until the defined temperature, holding it for a given time (freezing time) and then progressively leading it back to the room temperature. The aim is to obtain an improvement of mechanical properties, typically hardness and wear resistance, but in recent tests fatigue limit too, and to achieve an optimal ratio between conflicting properties, like hardness and toughness.

The research about CT has been validated by the first results on machinery tools, which have shown remarkably enhancement in hardness and durability. From the Nineties, the interest in CT effects has also been applied to many different components: i.e. motor racing parts [1], in particular gears and bearings [2-6], oil drills, gun barrels, knives, surgical and dental instruments [7] and even brass musical instruments [8], piano and guitar strings (Dean Markley Blue Steel ${ }^{\mathrm{TM}}$ ), baseball bats and golf clubs too. Nowadays, many companies offer CT services, especially in the USA and in Canada, and in some cases if no improvement in component life has been obtained they promise a refund.

Even though the mechanism behind improvement has not been totally clarified, different hypotheses coherently with microstructural observations have been suggested in literature.

The aim of the present review is to summarize the most significant works of the last thirty years, focusing on

*Address correspondence to this author at the Politecnico di Torino - Dipartimento di Meccanica, Corso Duca degli Abruzzi 24, 10129 Torino, Italy;

E-mail: paolo.baldissera@polito.it methods, parameters, results and assumed microstructural mechanisms, in order to give to the reader a starting point to approach the CT topic.

The work represents the first step of a research project carried out during the last three years by the authors in the context of a Ph.D. thesis, which will be discussed in early 2008. Due to some Italian law restrictions, all the results from the above research project will be available for publication only after Ph.D. thesis discussion; for this reason they are not included in the present paper.

\section{TREATMENT PARAMETERS}

A fundamental distinction among different $\mathrm{CT}$ is given by the parameters of the cooling-warming cycle. In [9] two families depending on the minimum temperature reached during the cycle are categorized:

- Shallow Cryogenic Treatment (SCT) or Subzero Treatment: the samples are placed in a freezer at 193 $\mathrm{K}$ and then they are exposed to room temperature;

- $\quad$ Deep Cryogenic Treatment (DCT): the samples are slowly cooled to $77 \mathrm{~K}$, held-down for many hours and gradually warmed to room temperature.

Fig. (1) shows an example of a common DCT temperature profile. The typical process parameters are: minimum temperature $\left(T_{\min }\right)$, hold time, cooling and warming rate. In literature, different values of these parameters used by authors during SCT and DCT on different materials can be found (see Table 1), but anyway it is possible to infer some general indications:

- In some cases, the actual $\mathrm{T}_{\min }$ could be higher than the nominal one because of thermal insulation limits, especially after a significant exploitation of the system and the consequent ageing of the chamber seals.

- $\quad$ Each new material needs to be treated and tested at different temperature levels, in order to identify optimum conditions. In most cases, two or three temperature levels (i.e. $88 \mathrm{~K}, 143 \mathrm{~K}$ and $193 \mathrm{~K}$ ) are enough to obtain a quick indication in the selection of a specific temperature by means of microstructural changes investigation (i.e. calorimetry or acoustic emission); 
Table 1. Literature Parameters of SCT and DCT on Different Materials

\begin{tabular}{|c|c|c|c|c|c|}
\hline First Author, [\#] & Material & $\mathbf{T}_{\min }[\mathbf{K}]$ & Ramp Down [K/min] & Hold Time [h] & $\operatorname{Ramp} \mathbf{U p}[\mathrm{K} / \mathrm{min}]$ \\
\hline Huang, [19] & AISI M2 tool steel & 77 & - & 168 & - \\
\hline da Silva, [15] & AISI M2 tool steel & 77 & 1.0 & 20 & 1.0 \\
\hline Leskovšek, [13] & AISI M2 tool steel & 77 & immersion & 1 & - \\
\hline Mohan, [39] & AISI M2, T1, D3 tool steel & from 163 to 93 & - & 6 and 24 & - \\
\hline Molinari, $[17,18]$ & AISI M2, H13 tool steel & 77 & from 0.3 to 0.5 & 35 & 0.07 \\
\hline Yun, [16] & AISI M2, T1 tool steel & 77 & - & 24 and 48 & - \\
\hline Gordo, [20] & M3/2 HSS matrix with $\mathrm{Nb}$ and Ta carbides & 77 & 0.36 & 35 & 0.07 \\
\hline Meng, [3] & $\mathrm{Fe}-12 \mathrm{Cr}-\mathrm{Mo}-\mathrm{V}-1.4 \mathrm{C}$ tool steel & 223 and 93 & - & - & - \\
\hline Meng, [4] & Fe-1.4Cr-1C bearing steel & 223 and 93 & - & 1 & - \\
\hline Bensely, $[9,22,41]$ & En 353 carburized steel & 193 and 77 & immersion and 1.24 & 5 and 24 & 0.64 \\
\hline Preciado, [21] & Carburized steel & 83 & 1.0 & 22 & - \\
\hline Kollmer, [40] & AISI 4140 cold rolled steel & 89 & 1.13 & $6-10$ & 1.13 \\
\hline Zhirafar, [12] & AISI 4340 low alloy steel & 77 & 1.8 & 24 & 1.8 \\
\hline Yong, [24] & ASSAB 760 medium carbon steel & 89 & 0.57 & 18 & 0.57 \\
\hline Yang, [46] & 13Cr2Mn2V high $\mathrm{Cr}$ white iron & 77 & immersion & 3 & - \\
\hline Liu, [45] & 3Cr13Mo1V1.5 high Cr cast iron & 77 & immersion & 3 & - \\
\hline Darwin, [10] & SR34 18\% Cr martensitic stainless steel & from 193 to 89 & from 0.5 to 3.5 & from 6 to 36 & 1.0 \\
\hline Ianamura, [28] & $\mathrm{Fe}-18 \mathrm{Cr}-8 \mathrm{Ni}$ austenitic stainless steel & 195 & - & - & - \\
\hline Myeong, [27] & Fe-18Cr- $8 \mathrm{Ni}$ austenitic stainless steel & 197 & - & 3 & - \\
\hline Singh, $[25,26]$ & AISI 304L welded joints & 88 & from 0.34 to 0.85 & 30 & from 0.17 to 0.34 \\
\hline Zhisheng, [47] & $\mathrm{Cr}-\mathrm{Zr}-\mathrm{Cu}$ alloy electrodes & 123 and 103 & 6.0 & 2 and 4 & - \\
\hline Chen, [32] & $\mathrm{Al}$ alloy & 89 & - & 24 & - \\
\hline Lulay, [33] & 7075-T651 Al alloy & 77 & - & 2 and 48 & - \\
\hline Trieu, [31] & UHMWPE & 89 & 0.5 & 14 & - \\
\hline
\end{tabular}

- $\quad$ Hold time over 36 hours does not bring significant improvements and in most cases 24 hours are enough to obtain results;

- Cooling rate values range is restricted in order to prevent thermal-shock cracking. Commonly, the applied values vary from $0.3 \mathrm{~K} / \mathrm{min}$ to $1.2 \mathrm{~K} / \mathrm{min}$;

- In many cryogenic systems warming rate is not closely controllable and little importance to this parameter is given in literature despite of some suggested hypothesis about carbides precipitation during the warming phase.

In [10], the Taguchi Design of Experiment (DOE) method is applied to identify and to optimize the critical parameters of DCT on a $18 \% \mathrm{Cr}$ martensitic stainless steel used for piston rings. The Analysis of Variance (ANOVA) of wear test results has pointed out that the most significant factor has been the soaking temperature $(72 \%$ in contribution), followed by the soaking time $(24 \%)$ and the cooling

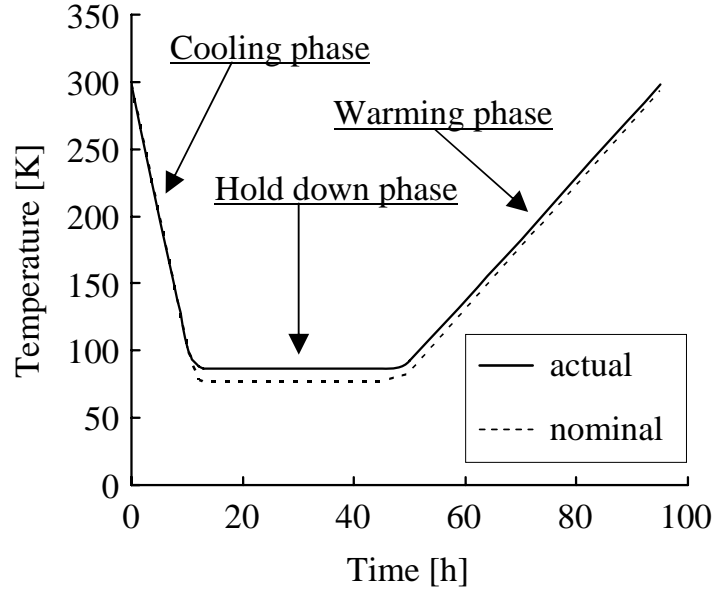

Fig. (1). Example of DCT temperature profile. 
rate $(10 \%)$. Little importance $(2 \%)$ for the temperature of the tempering process performed after DCT has been observed, while the tempering time is emerged as an irrelevant parameter. Little or no significance for parameters interactions has been calculated and in the end the authors have obtained an optimal combination of $89 \mathrm{~K}$ soaking temperature, 36 hours soaking time, $1 \mathrm{~K} / \mathrm{min}$ cooling rate and 1 hour tempering at $523 \mathrm{~K}$, predicting a wear loss of $2.26 \mathrm{mg}(95 \%$ in confidence). A test performed on samples treated with these parameters has confirmed the result.

\section{CRYOGENIC SYSTEMS}

A cryogenic system is an equipment which allows to control temperature in the cryogenic range into a chamber, using liquid nitrogen or helium.

Until the end of the Sixties, any attempt to perform CT had been done by direct immersion into liquid nitrogen, with the catastrophic result of cracking the components. The cryogenic treatment system developed by Ed Busch (CryoTech, Detroit, MI) in the late 1960s and later improved by Peter Paulin (300 Below Inc., Decatur, IL) with a temperature feedback control on cooling and heating rate, allows to perform effective and crackless CT. As a result, many companies have developed systems to perform CT, mainly in the USA and in Canada, but also in China, India and Japan.

The three most important cooling systems are described in [11]:

- Heat Exchanger: the liquid nitrogen flows through a heat exchanger and the output cooled gas is diffused inside the chamber by a fan. There is no contact between nitrogen and samples;

- Direct Nebulization: the liquid nitrogen is nebulized directly in the chamber or in a cavity around the chamber. A fan allows to obtain a homogeneous temperature distribution; the liquid nitrogen is dispersed around the samples;

- Gradual Immersion: the samples are immersed into the liquid nitrogen for a specific time, then they are extracted and gradually led back to the room temperature by means of a flow of temperature controlled air.

Another type of cooling system is the so-called "Hybrid System", which combines direct nebulization and gradual immersion during different phases of the cooling process, in order to reduce liquid nitrogen consumption (i.e. VariCold ${ }^{\mathrm{TM}}$ from Cryotron, Canada).

Fig. (2) shows the layout of a direct nebulization cryogenic system. The Control Unit (CU) receives the temperature information from the sensor $(\mathrm{S})$ placed in the chamber (C). The CU operates on the electrovalve (EV) by the regulation of the liquid nitrogen flow through the injectors (I). The fan $(F)$, which is controlled by an electric engine $(E)$, helps to diffuse the nitrogen homogeneously. The $\mathrm{CU}$ allows to control the cycle parameters and it provides a print of timetemperature diagram. In a direct nebulization system with a chamber of about $0.25 \mathrm{~m}^{3}$, an ordinary cycle, requires from 10001 to 20001 of liquid nitrogen usually stored in a tank (T), depending on cycle parameters and on the treating material quantity.

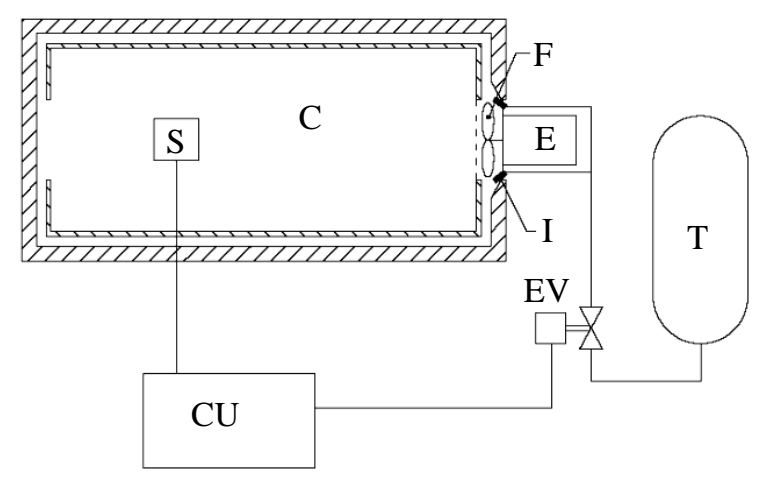

Fig. (2). Sketch of a direct nebulization cryo-system.

\section{EFFECTS ON THE MATERIAL MICROSTRUCTURE}

\section{Ferrous Alloys}

According to the literature about cryo-treated tool steels, the improvement of mechanical properties can be ascribed to different phenomena:

- Complete transformation of the retained austenite into martensite;

- $\quad$ Fine dispersed carbides precipitation;

- Removal of residual stresses.

It is known that almost all steels at $193 \mathrm{~K}$ transform the austenite into martensite. The use of cold treatment has been initially developed on martensitic tool steels in order to remove retained austenite with benefits on hardness.

A reduction from $5.7 \%$ to $4.2 \%$ in retained austenite volume has been measured after DCT by the use of neutron diffraction on AISI 4340 steel [12]. The temperature reached in SCT is enough to obtain this result, therefore the use of a lower temperature by DCT can only be justified if it activates some different phenomena which lead to a further improvement of the mechanical properties. In [13], a reduction in retained austenite fraction and a rod-like carbides precipitation during tempering after DCT have been observed, pointing out a correlation between the carbide dimension and the tempering temperature. Moreover the authors have obtained a greater dimensional stability of DCT components after each subsequent tempering, which is a result strictly related to the retained austenite elimination, thanks to the lower volume compared to the martensite. The dimensional stability is a desired property for some accurate applications as worn plug gages [14]. The X-ray diffractometric observations carried-out in [15] have confirmed both phenomena: $25 \%$ of the retained austenite observed before DCT treatment has been transformed into martensite and fine carbides precipitation has been promoted. Most of the authors, especially in recent papers, have agreed on ascribing to the fine carbides precipitation the improvement of the wear behavior.

Precipitation of fine dispersed carbides has also been previously observed in AISI T1 and M2 high-speed tool steels [16] and in AISI H13 tool steel [17, 18] where, after DCT, the disappearing of twinned submicrostructures present in tempered martensite has been noted. The authors have called this phenomenon "tempered martensite detwinning" but no information is available in literature about 
something similar. Fine $\eta$-carbides in cryo-treated $\mathrm{Fe}-12 \mathrm{Cr}$ Mo-V-1.4C tool steel has been observed with TEM [3, 4]; the authors have proposed a precipitation mechanism based on the contraction and the expansion of the martensitic lattice in different directions, with a slightly shifting of carbon atoms, in order to segregate $\eta$-carbides along the carbon-rich bands. The effect is an improved wear resistance ascribed by the authors to the strength and the toughness enhancement of the martensite matrix.

An interesting analysis of possible phenomena inside the material during the $\mathrm{CT}$ is proposed in [19]. By measuring the presence of spherical Fe4M2C (where $\mathrm{M}=\mathrm{W}, \mathrm{Mo}, \mathrm{Cr}, \mathrm{V}$ ) carbides in M2 steel before and after DCT, the authors have found that particles size-range and size-distribution are similar in treated and non-treated samples, but the population and the volume fraction are different and the carbides distribution is more homogeneous in treated samples. Moreover, the carbides volume fraction is increased from $5 \%$ to $11 \%$ after DCT. The authors suggest that, during the cooling, microscopic internal stresses are generated by different thermal contractions due to the composition and to the microstructure spatial variation; as a consequence, there is a generation of dislocations and of twins, where carbon and alloying atoms subsequently segregate. The hypothesis of this localized diffusion process is in the agreement with the long holding time normally required in CT. Furthermore in the same article the hypothesis for which also the reduction in residual stresses, reported by other authors, could be a consequence of carbides precipitation has been proposed. Quoting a private communication with M.A. Bourke, the authors suggest that the precipitation mechanism could be related to different behaviors of lattice parameters $c$ and $a$ during the cooling and the warming-up processes observed through an in-situ neutron diffraction study.

An interesting result on tools built with different classical AISI steels has been obtained in [20], using DCT on HSS base composites reinforced with $\mathrm{Nb}$ and $\mathrm{Ta}$ carbides with a high level of retained austenite. The authors have achieved the transformation of retained austenite into martensite, with the consequent increase in hardness and a fine carbides precipitation in the matrix.

Concerning the carburized steels commonly used for gears [9], with the help of an optical microscope it has been observed that both retained austenite elimination and fine carbides precipitation are effective DCT mechanisms, whereas in SCT only the first mechanism acts in the material. Fine carbides precipitation has been observed in a carburized steel in [21] too, but no decrease of retained austenite fraction has been detected.

An important role for the improvement of the mechanical performance of materials and components is played by the residual stress distribution. This aspect of CT has been well analyzed in [22] on a carburized EN 353 steel. The authors have measured the residual stress distribution using X-ray diffraction on conventionally heat treated, SCT and DCT samples in both tempered and untempered condition. They have observed that residual stress distribution is strictly related to both retained austenite reduction and fine carbides precipitation mechanisms. On the one hand, untempered DCT specimens have shown an increase (from -125 MPa to $-235 \mathrm{MPa}$ ) in surface compressive residual stress, as a con- sequence of DCT retained austenite reduction from $28.1 \%$ to $14.9 \%$. On the other hand, after a necessary tempering (otherwise the following grinding would have led to crack formation in all specimens, independently of treatment), the surface residual stress in DCT specimens has dropped to -80 $\mathrm{MPa}$, while in a conventionally heat treated it has risen to $-150 \mathrm{MPa}$. This overturning has been attributed by the authors to the stress relieving loss of martensite tetragonality, which is caused by the carbides precipitation and which in its turn has been promoted during tempering just by previous DCT-enhanced compressive stress state. From these results it is possible to infer that compressive residual stress and fine carbides precipitation, which are both mechanical performance enhancing mechanisms, move into opposite directions during tempering. As a consequence, understanding and controlling the optimal ratio between them could be the key for achieving best results.

With the aim of understanding microstructural changes and phases evolution during DCT and the subsequent tempering, an important role can be played by the recent development of numerical heat treating modeling techniques. An approach to DCT numerical simulation is proposed in [23]. The authors have implemented an optimization algorithm in a commercial heat treatment simulation software package $\left(\mathrm{DANTE}^{\mathbb{B}}\right.$ ), in order to calculate phase transformation kinetic parameters, starting from dilatometry experimental results. The simulation involves the whole thermal treatment process including heating, carburizing, quenching, DCT and tempering for a bar model with a notch on the top surface. The model predicts a reduction in retained austenite content and subsequent additional compressive stress in the top surface after DCT and tempering, compared to as-quenched condition. On the contrary, experimental results used for model validation have indicated a lower superficial compressive stress after DCT and tempering. The authors have attributed this difference to a wrong assumption of balanced biaxial stress in the case of measured stress calculations, but the similarity with the results reported in [22] legitimizes to suspect that the reason of the gap could be the unpredicted carbides precipitation during the final tempering simulation.

It is interesting to observe that a recent work [24] states that cryo-treated tools can lose their wear resistance when they are subjected to prolonged periods of high temperature at the cutting edge. Hence, the authors have concluded that the state of the material after CT is metastable, but in the light of what is stated in [22] and reported above, this loss can be explained as an overtempering effect due to a prolonged high temperature working, with the consequent relief of beneficial compressive residual stress.

According to the literature, a totally different mechanism occurs during CT of austenitic stainless steels. The effect of DCT on welded cruciform joints of AISI 304L austenitic stainless steel has been investigated in [23, 24]: the crack initiation life has been extended by strain-induced martensite formed during CT. In addition, the authors have observed a different residual stress configuration near the welded metal after DCT: the tensile residual stresses have been relieved and a compressive stress field has been induced as a consequence of expansion of the weld metal during this transformation. While in [25] the authors have found a slight decrease of $m$ and $C$ Paris constants after DCT, indicating a 
reduction in crack growth rate, the result has not been confirmed in [26] by the same authors. In the discussion about crack initiation life extension, the authors have suggested a dislocation-pinning mechanism in agreement with the TEM observation and with the diffractometric analysis performed in [27-29], which have revealed the presence of nanomartensitic particles in pre-strained austenitic stainless steels after an SCT performed with a few hours hold-time at $3 \mathrm{~K}$ above Ms (martensite start temperature).

\section{Non-Ferrous Alloys}

Despite of the advertisement on cryo-companies web sites, which promises enhancement on a wide range of materials, there are few papers in literature about $\mathrm{CT}$ of nonferrous materials. In [30], the DCT effects on a wide range of polymers and composites have been tested, pointing out interesting results for some of them. Using X-ray diffraction the authors have found a marginal increase in cristallinity after the DCT on Polyetherimide (PEI) and on Polyimide (PI), while no changes have been detected on Polytetrafluoroethylene (PTFE). The change in cristallinity of PEI has been confirmed by Differential Scanning Calorimetry (DCS), which has shown an increase of the glass transition temperature $\left(\mathrm{T}_{\mathrm{g}}\right)$ from $488 \mathrm{~K}$ to $526 \mathrm{~K}$. The authors have related the increase in wear resistance of PEI and of PI to the change in cristallinity. Moreover, Scanning Electron Microscopy (SEM) has pointed out a rougher topography for the surface of the cryotreated PEI. In order to explain these observations, the authors have suggested the development of residual stresses in the polymer as a consequence of the contraction at cryogenic temperatures and subsequent uneven expansion during the warming phase. In the case of the PTFE, the improvement in wear behavior after the DCT has been attributed to the hardness enhancement. In addition, the SEM observations of PTFE powder have shown agglomeration and fibrillation phenomena after DCT, which the authors have related to the ductile behavior, at low temperature too, of PTFE.

Any significant or detectable changes in dimension, cristallinity, tensile strength and elongation on Ultra-High Molecular Weight Polyethylene (UHMWPE) samples after DCT has been found in [31].

The heat affected zone of an unspecified aluminum alloy, which has been welded with Variable Polarity Plasma Arc (VPPA) technique, has been investigated before and after
DCT in [32]. Using X-ray diffractometry, the authors have detected a reduction in residual stresses, but no microstructural analysis has been performed.

DCT has also been performed on 7075 aluminum alloy samples [33], but the authors did not find any enhancement in tensile, impact and hardness properties and no further analysis about the material structure has been carried out.

\section{EFFECTS ON THE MECHANICAL PROPERTIES}

An extensive collection of CT test results is reported in [34-38] concerning hardness and wear resistance of a wide range of steel grades. This series of papers represents a milestone in the CT field. The papers $[37,38]$ show wear and hardness results for respectively twelve tool steels, three stainless steels and four other steels. By comparing the results obtained with $189 \mathrm{~K} \mathrm{SCT}$ and $77 \mathrm{~K} \mathrm{DCT}$, the authors have observed a significant abrasive resistance increase for the tool steels subjected to the colder treatment, whereas the stainless steels have shown a difference of less than $10 \%$ and the plan carbon and the cast iron did not improve with either SCT and DCT.

After the investigations carried out in papers [34-38] many works reporting test results on CT materials have been published, but each one has focused on one or on few materials instead of collecting data from many of them. As a consequence, it can be helpful to summarize the published results in order to have an overall picture of the measured effects. Table 2 gives some general indications about CT effects on mechanical properties reported by the literature on five steel types and on aluminum alloys. A brief discussion about effects on each property is proposed in the following paragraphs.

\section{Wear Resistance}

Wear resistance represents an important property of a material when it is used in applications that lead to reciprocal moving of in-contact components, such as machining tools, bearings, gears, brake rotors, piston seals, etc. Among the listed above microstructural changes related to CT, both retained austenite reduction and carbide precipitation can lead to an improvement in wear resistance by the increase of the steel hardness.

It is almost impossible to carry out a complete comparison between the results obtained in literature, because of different test conditions (such as sliding velocity, distance or

Table 2. Literature Effects of SCT and DCT on Different Materials

\begin{tabular}{|c|c|c|c|c|c|c|c|c|c|c|c|c|}
\hline & \multicolumn{2}{|c|}{$\begin{array}{c}\text { Tool } \\
\text { Steels }\end{array}$} & \multicolumn{2}{|c|}{$\begin{array}{l}\text { Carburized } \\
\text { Steels }\end{array}$} & \multicolumn{2}{|c|}{$\begin{array}{l}\text { Austenitic Stain- } \\
\text { less Steels }\end{array}$} & \multicolumn{2}{|c|}{$\begin{array}{c}\text { Martensitic } \\
\text { Stainless Steels }\end{array}$} & \multicolumn{2}{|c|}{$\begin{array}{c}\text { High Cr Cast } \\
\text { Iron }\end{array}$} & \multicolumn{2}{|c|}{$\begin{array}{c}\text { Aluminum } \\
\text { Alloy }\end{array}$} \\
\hline & SCT & DCT & SCT & DCT & SCT & DCT & SCT & DCT & SCT & DCT & SCT & DCT \\
\hline Hardness & na & + & + & + & na & + & na & + & na & + & na & $=$ \\
\hline Wear resistance & + & + & + & + & na & na & na & + & na & + & na & na \\
\hline Fatigue life & na & na & na & na & + & + & na & + & na & na & na & $=$ \\
\hline Toughness & na & + & na & na & na & na & $=$ & - & na & na & na & + \\
\hline
\end{tabular}


applied load) used by the authors and different wear indicators reported as results (i.e. wear rate or wear resistance).

The most experimented effect of CT is the enhancement of the wear resistance, especially on tool steels. Table $\mathbf{3}$ shows the wear resistance improvement reported in literature, after the publications [34-38] about different materials and test configuration. Different setup are reported in literature for wear test, but the most used configuration is the pinon-disk, according to the ASTM standards and the results are usually reported in terms of wear resistance or of wear rate. Some authors have also performed tests directly on cryotreated tools, by measuring the tool life in number of worked pieces, in the so-called "flank-wear test" or in the "twist drill test".

As it is shown in Table 3, one of the most cryo-tested materials is AISI M2 high speed tool steel, which is widely used for drills, milling cutters and other tools. Wear resistance is an important property not only for tools, but also for many components subjected to rolling or sliding contact, in different industrial fields like automotive, mining, oildrilling, etc. Some studies about effects of CT on bearingsteels and carburized steels used in automotive industries are available in literature (i.e. En353 has a significant application for crown wheel, crown pinion, bevel pinion, bevel wheel, timing gears, king pinion, pinion shaft).
Many authors agree with [3] about the reason of the wear resistance improvement: it is the fine carbides precipitation that enhances strength and toughness of the martensite matrix, rather than the reduction or the elimination of the retained austenite fraction. In [17, 18], the wear rates of an AISI M2 tool steel have been compared after four different treatment combinations and sequences:

- $\quad$ Quenching then double tempering (A);

- $\quad$ Quenching, double tempering then DCT (B);

- $\quad$ Quenching, DCT then tempering (C);

- $\quad$ Quenching, DCT then double tempering (D).

The (B) samples have shown a reduction of $51 \%$ in wear rate compared with the (A) samples, against $40 \%$ and $35 \%$ for (C) and (D) specimens respectively. The authors have concluded that greater benefits are obtained when DCT is carried out after tempering process.

Another interesting comparison has been proposed in [39] between cryo-treated and TiN coated samples, which has shown that $\mathrm{CT}$ for 24 hours at $93 \mathrm{~K}$ is more effective on wear resistance than TiN coating. Through the comparison of the results of CT specimens treated with different parameters, the authors have also concluded that the mechanism responsible for the wear resistance improvement is essentially an isothermal process and the soaking time is more

Table 3. DCT Improvement of Wear Resistance in Literature

\begin{tabular}{|c|c|c|c|}
\hline First Author, [\#] & Material & Test Configuration & Maximum Wear Improvement \\
\hline \multirow{4}{*}{ da Silva, [15] } & \multirow{4}{*}{ AISI M2 tool steel } & Pin-on-disk & No significant changes \\
\hline & & Brandsma rapid facing tests & $+44 \%$ tool life \\
\hline & & Twist drills & $\begin{array}{l}+343 \% \text { tool life } \\
\text { (catastrophic failure end-life criterion) }\end{array}$ \\
\hline & & Shop floor test (special shaper milling cutter) & $\begin{array}{l}-22.8 \% \text { produced parts (appearance of burrs } \\
\text { end-life criterion) }\end{array}$ \\
\hline \multirow[b]{2}{*}{ Mohan, [39] } & \multirow[b]{2}{*}{ AISI M2, T1, D3 tool steel } & Pin-on-disk (M2, D3) & $\begin{array}{l}+135 \% \text { wear resistance for M2 } \\
+174 \% \text { wear resistance for D3 }\end{array}$ \\
\hline & & Flank wear (T1, M2, D3) & $\begin{array}{l}+110.2 \% \text { wear resistance for } \mathrm{T} 1 \\
+86.6 \% \text { wear resistance for M2 } \\
+48 \% \text { wear resistance for D3 }\end{array}$ \\
\hline Molinari, $[17,18]$ & AISI M2, H13 tool steel & Pin-on-disk & $\begin{array}{l}-51 \% \text { wear rate for } \mathrm{M} 2 \\
-29 \% \text { wear rate for } \mathrm{H} 13\end{array}$ \\
\hline Pellizzari, [43] & $\begin{array}{l}\text { X155CrMoV12 } \\
\text { X110CrMoV8 cold work tool steels }\end{array}$ & Block-on-disk dry sliding & $\begin{array}{l}-42.4 \% \text { wear rate for X155 } \\
-25.3 \% \text { wear rate for X110 }\end{array}$ \\
\hline Meng, [3] & Fe-12Cr-Mo-V-1.4C tool steel & Sample-on-wheel & " $110 \%$ to $600 \%$ improvement", p. 206 \\
\hline Meng, [4] & $\mathrm{Fe}-1.4 \mathrm{Cr}-1 \mathrm{C}$ bearing steel & Sample-on-wheel & $-50 \%$ wear rate $(*)$ \\
\hline Bensely, [9] & En 353 carburized steel & Pin-on-disk & $\begin{array}{l}+85 \% \text { wear resistance for } \mathrm{SCT} \\
+372 \% \text { wear resistance for DCT }\end{array}$ \\
\hline Preciado, [21] & Carburized steel & Pin-on-disk & $-20 \%$ wear rate $(*)$ \\
\hline Yong, [24] & ASSAB 760 medium carbon steel & Flank wear & $\begin{array}{l}-33 \% \text { flank wear }(*) \text { after } 300 \text { s of continu- } \\
\text { ous cutting }\end{array}$ \\
\hline Yang, [46] & 13Cr2Mn2V high $\mathrm{Cr}$ white iron & M-200 Abrasion Experimental Aircraft & $+8 \%$ relative wear ratio $(*)$ \\
\hline Liu, [45] & 3Cr13Mo1V1.5 high $\mathrm{Cr}$ cast iron & M-200 Abrasion Experimental Aircraft & $+5 \%$ relative wear ratio $(*)$ \\
\hline Darwin, [10] & SR34 18\% Cr martensitic stainless steel & Reciprocatory Friction Test & $-43,8 \%$ wear loss \\
\hline
\end{tabular}


important than the minimum temperature reached during the treatment. In addition, they have found CT to be more beneficial on untempered than on tempered samples.

The influence of the soaking temperature on DCT wear improvement has been confirmed in [10].

According to [30], the wear resistance of some engineering polymers and composites can be improved by DCT. The authors have obtained an increase up to $60 \%$ in abrasive wear resistance of cryotreated PTFE, while PEI and PI have shown improvements up to $35 \%$ and $58 \%$ respectively. In particular, the paper focus on the different responses to DCT, which have been obtained for the same polymeric matrix combined with different amouts and qualities of fibers or fillers. As an example, a $+30 \%$ in wear resistance have been reported for cryotreated PEI without fiber reinforcement, while the same material $40 \%$ glass fibers reinforced have shown a $-35 \%$ in wear performance after DCT. Some interesting results have been reported, in the same paper, for Polyetherimide Copolymer, for Polyurethane (PU) and for Polycarbonate.

\section{Hardness}

Many hardness tests about $\mathrm{CT}$ are reported in literature because this property is related to the wear resistance. Hardness properties are usually measured through indentation tests and they are espressed in different scales depending on the penetrator shape. The most used methods are the Rockwell and the Vickers ones. While the first method is a macroindentation test, the second one can be performed both as macro or micro-indentation, depending on the applied load, as performed in $[25,26]$. The hardness of a tool steel is mainly influenced by retained (soft) austenite and in this way CT can play an important role. However, when compared to wear results, hardness test results (see Table 4), indicate that the mechanisms can be different for different materials. For instance, in [17] a little increase $(+0.13 \%)$ in hardness has induced $\mathrm{a}-51 \%$ in wear rate for AISI M2 and the authors have concluded that AISI M2 wear resistance improvement can be attributed to hardness increase. The same test on AISI H13 tool steel has shown an improvement of $6.9 \%$ in hardness related to a decrease of $29 \%$ in wear rate and, according to the authors, the wear resistance improvement has been correlated to the enhanced toughness of the CT material.

The paper [13] suggests that playing on carbides fraction and dimension and on retained austenite allows to achieve an optimized ratio between hardness and toughness in high speed steels. Interesting results on HSS base composites reinforced with $\mathrm{Nb}$ and $\mathrm{Ta}$ carbides have been obtained, with about $10 \%$ increased hardness [20].

Concerning non-ferrous materials, no significant changes in hardness of aluminum alloys [32, 33] and of Ultra-high Molecular Weight Polyethylene [31] have been detected, while PTFE, PEI, PI, PU and PC have shown important changes in Shore D hardness [30].

\section{Tensile and Bending Strength}

A few tensile and bending test results have been published comparing properties before and after CT. This is

Table 4. DCT Improvement of Hardness in Literature

\begin{tabular}{|c|c|c|}
\hline First Author, [\#] & Material & Maximum Hardness Improvement \\
\hline da Silva, [15] & AISI M2 tool steel & No significant changes \\
\hline Leskovšek, [13] & AISI M2 tool steel & $+5.26 \%$ Rockwell-C hardness \\
\hline Molinari, $[17,18]$ & AISI M2, H13 tool steels & $\begin{array}{l}+8.3 \% \text { Vickers hardness on M2 } \\
+6.9 \% \text { Rockwell-C hardness on } \mathrm{H} 13\end{array}$ \\
\hline Yun, [16] & AISI M2, T1 tool steels & $\begin{array}{l}+2.6 \% \text { Rockwell-C hardness on M2 } \\
+2.8 \% \text { Rockwell-C hardness on } \mathrm{T} 1\end{array}$ \\
\hline Pellizzari, [43] & AISI H13 tool steel & $+6.9 \%$ Rockwell-C hardness \\
\hline Pellizzari, [44] & $\begin{array}{l}\text { X155CrMoV12 } \\
\text { X110CrMoV8 cold work tool steels }\end{array}$ & No significant changes on both steels \\
\hline Gordo, [20] & M3/2 HSS matrix composite with $\mathrm{Nb}$ and Ta carbides & $+12.35 \%$ Rockwell-C hardness \\
\hline Bensely, [9] & En 353 Carburized steel & $+3.48 \%$ Vickers hardness \\
\hline Jordine, $[5]$ & En36A carburized steel & $+17 \%$ Vickers hardness $(*)$ \\
\hline Preciado, $[21]$ & Carburized steel & $+17 \%$ Vickers microhardness $(*)$ \\
\hline Kollmer, [40] & AISI 4140 cold rolled steel & No significant changes \\
\hline Zhirafar, [12] & AISI 4340 low alloy steel & $+2.4 \%$ Rockwell-C hardness \\
\hline Yang, [46] & $13 \mathrm{Cr} 2 \mathrm{Mn} 2 \mathrm{~V}$ high chromium white iron & $+3.2 \%$ Rockwell-C hardness $(*)$ \\
\hline Liu, [45] & $3 \mathrm{Cr} 13 \mathrm{Mo} 1 \mathrm{~V} 1.5$ high chromium cast iron & $+5.5 \%$ Rockwell-C hardness $(*)$ \\
\hline Singh, $[25,26]$ & AISI 304L welded joints & $\begin{array}{l}\text { No changes in macrohardness }(10 \mathrm{~kg}) \\
+18.8 \% \text { in Vickers microhardness }(50 \mathrm{~g})\end{array}$ \\
\hline Zhisheng, [47] & $\mathrm{Cr}-\mathrm{Zr}-\mathrm{Cu}$ alloy electrodes & $+3.13 \%$ Brinell hardness \\
\hline Lulay, [33] & 7075-T651 Al alloy & No significant changes $(-0.5 \%)$ \\
\hline
\end{tabular}


mainly due to the fact that tensile properties are less relevant than hardness and wear resistance in tool steels, which are the most studied materials in the CT literature. Furthermore, static properties are expected to be not strongly affected by retained austenite fraction, while concerning precipitation strengthening it is supposed that very small precipitates can be easily bypassed at high stress levels by the dislocation climbing mechanism. However, the only published results about tool steel refer to AISI M2 and T1 and indicate a remarkable improvement of about $20 \%$ and of $25 \%$ respectively in bending strength [16]. In [40], an increase from 7\% to $16 \%$ in tensile strength of 4140 cold rolled steel specimens has been detected after CT.

In [41], a slight reduction in tensile strength has been measured for a carburized steel-815M17 subjected to CT, compared to the same material conventionally treated. In particular the authors have observed a decrease of $1.5 \%$ for SCT and of $9.34 \%$ for DCT.

The cryogenic treatment does not seem to be effective on tensile properties of AISI 304 and 316 stainless steels [27-29].

No significant changes in tensile properties have been detected on aluminum alloys [32, 33] and on UHMWPE [31].

\section{Fatigue Resistance}

Fatigue of materials has been one of the most important research topics from the beginning of the $20^{\text {th }}$ century until today in the area of materials and mechanical engineering. All the above listed CT microstructural changes are related to the fatigue behavior, someone with beneficial effects and other ones with detrimental effects. A field of fine hard carbides or the presence of nano-sized martensite in an austenitic matrix can be the effective mechanisms in delaying or blocking dislocations motion at low stress amplitude, when dislocation climbing is unlikely to appear. From this point of view, on the one hand the observed DCT fine carbides precipitation can lead to a prolonged crack nucleation phase. On the other hand, the retained fraction of ductile austenite can act as a crack arrestor in the propagation phase and then its reduction could have a detrimental effect on the final stage of fatigue. In addition, the residual stresses too play an important role in crack nucleation mechanism, in particular during the bending fatigue. Therefore it is necessary to weigh up all these effects, in order to understand the fatigue results.

Despite of their great importance in many mechanical applications, fatigue properties of CT steels have not been investigated by many authors [42] is the oldest paper found in literature about low temperature treatment and fatigue strength. The authors have subjected a cold rolled steel to two different DCT: a rapid treatment by direct immersion in liquid nitrogen for 1 hour, a slow treatment by controlled cooling and 30 minutes holding time. Bending fatigue test results on treated and non-treated specimens have shown no differences in mean values of fatigue limit, but a smaller dispersion for DCT samples has been found. In addition, the authors have carried out an acoustic spectra analysis finding clear differences in the amplitude of harmonics of DCT specimens, but no microstructural changes have been detected in metallographic and fractographic inspections. For this reason the authors have suggested a residual stresses effect, supposing a connection with the redistribution of the lattice defects.

Some studies about CT and fatigue have been conducted at the Precision and Intelligence Laboratory of the Tokyo Institute of Technology [27-29]. During these researches the authors have measured the Ms (martensite start temperature) of a stainless steel with the acoustic emission technique, then they have cooled the samples just $3 \mathrm{~K}$ above Ms and they have returned the samples to the room temperature. In [27] the test has been conducted on an austenitic $\mathrm{Fe}-18 \mathrm{Cr}-8 \mathrm{Ni}$ stainless steel pre-strained by $2 \%$ in order to increase the dislocation density. The result, as reported in Fig. (3), have shown that the CT does not increase the fatigue life in the low-cycle regime $\left(<10^{4}\right.$ cycles $)$. However, CT samples have shown longer life in high-cycle regime $\left(>10^{4}\right.$ cycles). Considering a maximum stress of $350 \mathrm{MPa}$, the number of cycles to failure is about four and five times larger in CT specimens than in non-treated ones. In addition, the authors have found that at a maximum stress of $310 \mathrm{MPa}$ (just above the fatigue limit), the number of cycles to failure has been $2.8 \cdot 10^{5}$ for non-treated samples whereas subzero treated specimen did not fail at $1.7 \cdot 10^{7}$ cycles, ( $>60$ times longer). In [28], the same material has been pre-strained by $10 \%$ and subjected to the same subzero treatment, obtaining an extension of fatigue life of more than 10 times. Similar results have been found on AISI 304 (2\% and $10 \%$ pre-strained) and on AISI 316 samples [29]. The authors have stated that by controlling dislocation density and temperature it is possible to control the size of martensite in the material; they have also suggested that the nano-sized martensite formed at intersection of two partial dislocations is effective in pinning dislocation, with the result of extending fatigue life by prolonging the nucleation phase.

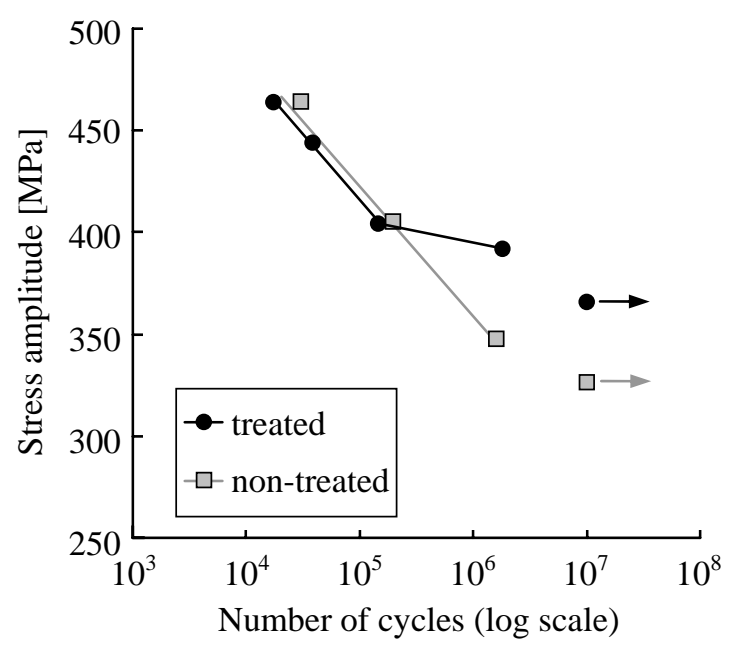

Fig. (3). Fatigue life extension of $\mathrm{Fe}-18 \mathrm{Cr}-8 \mathrm{Ni}$ austenitic stainless steel (from [28]).

A slight increase (25-30 MPa on about $600 \mathrm{MPa}$ ) in fatigue limit has been also measured in [12] for the rotating fatigue test on AISI 4340 steel. The authors have attributed this result to the slight increase in hardness, but they did not propose any microstructural mechanism for the explanation of the phenomenon. 
Concerning non-ferrous materials, a high-cycle fatigue test has been performed at room temperature on an unspecified aluminum alloy as-welded and cryo-treated, which has not shown a noticeable improvement [32].

\section{Thermal Fatigue Resistance}

In many engineering applications, in particular for internal combustion engines, the combination of thermal and mechanical cycles is a normal operational requirement and therefore it could be interesting to perform an analysis of CT effects on the thermomechanical fatigue behavior of materials. Nevertheless, the only study which has been published until now is a preliminary test about effect of DCT on purethermal fatigue properties, without mechanical loads [43]. By subjecting a rotating disk to a cyclic induction-warming and water-cooling (from $353 \mathrm{~K}$ to $973 \mathrm{~K}$ ) a crack network has been generated on its surface. After measuring the thermal crack density $\rho$, the mean crack length $l_{m}$ and the maximum crack length $P_{\max }$, the authors have calculated the pyrocracking factor $C$ as the product of these values. The DCT disk has shown a pyrocracking factor of $0.6 \mu \mathrm{m}$ against 1.18 $\mu \mathrm{m}$ of the untreated one. The parameter responsible for this decrease has been the crack density, which has reduced from $3.49 \mathrm{~mm}^{-1}$ to $1.53 \mathrm{~mm}^{-1}$. The mean crack length and the maximum crack length have remained almost the same for DCT and non-DCT samples, leading the authors to conclude that DCT can delay the crack nucleation process without increasing the propagation.

\section{Fracture Toughness}

Fracture toughness is a measure of the breaking resistance of a material which contains a crack. Together with the fatigue behavior, fracture toughness is one of the keys of the design applications of the last century. As mentioned in the Fatigue Resistance paragraph, retained ductile austenite fraction can play the role of crack arrestor in martensitic steels, enhancing the toughness.

In [13], the authors have suggested that carbides fraction and dimension and retained austenite fraction play an important role in the optimization of the ratio between hardness and toughness of high speed steels. The authors did not performed any test to measure fracture toughness $K_{I C}$, but they have used a semi-empirical equation proposed by themselves to calculate it, pointing out a decrease in toughness after CT:

$$
K_{I C}=\frac{1.363 \cdot H R c}{H R c-53} f_{\text {carb }}^{-1 / 6}\left(1+f_{\text {aust }}\right) \sqrt{E d_{p}},
$$

where $H R c$ is the Rockwell-C hardness, $f_{\text {carb }}$ and $f_{\text {aust }}$ the volume fractions of undissolved eutectic carbides and retained austenite, $E$ the Young elastic modulus expressed in $\mathrm{MPa}$, and $d_{p}$ is the mean distance between undissolved eutectic carbides in the matrix. The value of $d_{p}$ has been estimated by the authors by measuring the mean diameter of undissolved carbides $D_{p}$ from a $1000 \times$ magnification image obtained with a Scanning Electron Microscope (SEM) and using:

$$
d_{p}=D_{p}\left(1-f_{c a r b}\right) \sqrt{\frac{2}{3 f_{c a r b}}} .
$$

It is evident that an higher fraction of smaller carbides leads to lower values of $d_{p}$ and $K_{I C}$. It is also evident the role played by $d_{p}, f_{\text {carb }}$ and $f_{\text {aust }}$ in controlling the ratio between $H R c$ and $K_{I C}$.

In contrast with the results of [13], the Charpy impact tests reported in $[17,18,44]$ have shown an increase of $K_{I C}$ on AISI H13 tool steel after a double tempering and a DCT, without any effect on hardness and impact energy. The impact toughness before and after DCT on M2 and T1 tool steels has been measured in [16], obtaining an increase of about $43 \%$ and $58 \%$ respectively. No DCT effect on toughness has been found on 4140 cold rolled steel [40].

An evident toughness drop (14.3\%) after DCT has been observed in [12] on AISI 4340 steel; the authors have attributed this decrease to the higher martensite content of the cryotreated samples.

A slight increase $(+11.8 \%)$ of the impact toughness $J$ after 48 hours DCT on a 7075 aluminum alloy has been measured in [33], with a confidence level of about $90-95 \%$.

\section{CONCLUSIONS}

According to the literature, the initial mistrust about CT effect on mechanical properties of materials appears to be now cleared up, especially in the field of tool steels. The most relevant conclusions through a literature examination can be summarized as follows:

- Cryogenic systems allow to control important cycle parameters such as cooling rate, minimum reached temperature and soaking time. The choice of optimal treatment parameters requires specific investigations on each material, but in the case of steels some useful indications can be inferred from published works;

- Wear resistance and hardness improvement have been widely confirmed by published papers, especially by the ones concerning tool steels. Beneficial effects of $\mathrm{CT}$ on toughness and fatigue behavior have also been claimed by some authors. With few rare exceptions, no noticeable effects on tensile properties have been found in literature;

- $\quad$ Fine dispersed $\eta$-carbides precipitation appears to be effective on the wear resistance DCT improvement of tool steels rather than the retained austenite elimination, that is reached with SCT too;

- $\quad$ The only proposed microstructural mechanism for fine carbides precipitation in tool steels is the martensite contraction, due to thermal stresses during cooling, which leads carbon atoms to segregate near lattice defects;

- In the fatigue strengthening field, further investigations are necessary, for example, on the nano-martensite formation mechanism for austenitic steels, on the dislocation pinning effect produced by a field of fine hard carbides in martensitic steels and on the contribution of retained austenite and of residual stresses;

- $\quad$ CT effect on the thermal and thermo-mechanical fatigue behavior could be an interesting research field;

- Considering the improvements in wear and hardness of PTFE, PI and PEI, further investigations about the effects of CT on mechanical properties of polymers and composites could be a stimulating research topic. 


\section{REFERENCES}

[1] Schiradelly, R. and Diekman, F. J. "Cryogenics - The Racer's Edge", Heat Treating Progress, pp. 43-50, November 2001.

[2] P. Paulin, "Frozen gears", The Journal of Gear Manufacturing, pp. 26-29, Mars/April 1993

[3] F. Meng, K. Tagashira, R. Azuma and H. Sohma, "Role of etacarbide precipitations in the wear resistance improvements of $\mathrm{Fe}$ $12 \mathrm{Cr}-\mathrm{Mo}-\mathrm{V}-1.4 \mathrm{C}$ tool steel by cryogenic treatment", ISIJ Int., vol. 34(2), pp. 205-210, 1994.

[4] F. Meng, K. Tagashira and H. Sohma, "Wear resistance and microstructure of cryogenic treated Fe-1.4Cr-1C bearing steel", Scripta Metall. Mater., vol. 31(7), pp.865-868, 1994.

[5] A. Jordine, "Increased life of carburised race car gears by cryogenic treatment", Int. J. Fatigue, vol. 18(6), p. 418, 1996.

[6] R. N. Wurzbach and W. DeFelice, "Improving component wear performance through cryogenic treatment", in Lubrication Excellence 2004 Proceedings, 2004. [Online] Available: www.cryo plus.com [Accessed Nov. 11, 2007].

[7] J. W. Kim, J. A. Griggs, J. D. Regan, R. A. Ellis and Z. Cai, "Effect of cryogenic treatment on nickel-titanium endodontic instruments", Int. Endod. J., vol. 38(6), pp. 364-371, 2005.

[8] J. N. Jones and C. B. Rogers, "Chilling trumpets: does it have an acoustic effect?", in 146th Acoustical Society of America Meeting, 2003. [Online] Available: http://www.acoustics.org/ [Accessed Nov. 30, 2007].

[9] A. Bensely, A. Prabhakaran, D. Mohan Lal and G. Nagarajan, "Enhancing the wear resistance of case carburized steel (En 353) by cryogenic treatment", Cryogenics, vol. 45, pp. 747-754, 2005.

[10] J. D. Darwin, D. Mohan Lal and G. Nagarajan, "Optimization of cryogenic treatment to maximize the wear resistance of $18 \% \mathrm{Cr}$ martensitic stainless steel by Taguchi method", J. Mater. Process. Technol., Article in press, Corrected Proof, doi:10.1016/j.jmatprotec.2007.05.005

[11] D. M. Rusiñol, "Efecto del tratamento cryogénico en las propiedades mecànicas de los aceros de herramienta de trabajo en frìo", M.S. tesi, Escola Tècnica Superior d'Engynieria Industrial de Barcelona, Spain, 2004.

[12] S. Zhirafar, A. Rezaeian and M. Pugh, "Effect of cryogenic treatment on the mechanical properties of 4340 steel", J. Mater. Process. Technol., vol. 186, pp. 298-303, 2007.

[13] V. Leskovšek and B. Ule, "Influence of deep cryogenic treatment on microstructure, mechanical properties and dimensional changes of vacuum heat-treated high-speed steel", Heat Treat. Met., vol. 3, pp. 72-76, 2002.

[14] I. A. Revis, A. M. Levinson, V. S. Naletov and S. A. Popov, "Use of cryogenic treatment to restore worn plug gages", Chem. Petrol. Eng., vol. 10(5), p. 474, 1974.

[15] F. J. da Silva, S. D. Franco, E. O. Ezugwu, A and M. Souza Jr., "Performance of cryogenically treated HSS tools", Wear, vol. 261, pp. 674-685, 2006.

[16] D. Yun, L. Xiaoping and X. Hongshen, "Deep cryogenic treatment of high-speed steel and its mechanism", Heat Treat. Met., vol. 3, pp. 55-59, 1998 .

[17] A. Molinari, M. Pellizzari, S. Gialanella, G. Straffelini and K. H. Stiasny, "Effect of deep cryogenic treatment on the properties of tool steel", in Proceedings of Conference on Advances Materials Processes Technologies, 1999, pp. 1461-1469.

[18] A. Molinari, M. Pellizzari, S. Gialanella, G. Straffelini and K. H. Stiasny, "Effect of deep cryogenic treatment on the mechanical properties of tool steels", J. Mater. Process. Technol., vol. 118, pp. 350-355, 2001.

[19] J. Y. Huang, Y. T. Zhu, X. Z. Liao, I. J. Beyerlein, M. A. Bourke and T. E. Mitchell, "Microstructure of cryogenic treated M2 tool steel", Mater. Sci. Eng. A, vol. 339, pp. 241-244, 2003.

[20] E. Gordo, F. Velasco, N. Candela, J. M. Torralba, M. Pellizzari and A. Molinari, "Cryogenic treatment on HSS base composites reinforced with $\mathrm{Nb}$ and Ta carbides", in Proceedings of EUROPM'99 Conference, 1999, pp. 75-82.

[21] M. Preciado, P. M. Bravo and J. M. Alegre, "Effect of low temperature tempering prior cryogenic treatment on carburized steels", J. Mater. Process. Technol., vol. 176, pp. 41-44, 2006.
[22] A. Bensely, S. Venkatesh, D. Mohan Lal, G. Nagarajan, A. Rajadurai and K. Junik, "Effect of cryogenic treatment on distribution of residual stress in case carburized En 353 steel", Mater. Sci. Eng. $A$, Article in press, Corrected Proof, doi:10.1016/j.msea. 2007.07. 035 .

[23] B. L. Farguson, Z. Li and A. M. Freborg, "Modeling heat treatment of steel parts", Comp. Mater. Sci., vol. 34, pp. 274-281, 2005.

[24] A. Y. L. Yong, K. H. W. Seah and M. Rahman, "Performance evaluation of cryogenically treated tungsten carbide tools in turning", Int. J. Mach. Tool. Manu., vol. 46, pp. 2051-2056, 2006.

[25] P. J. Singh, B. Guha and D. R. G. Achar, "Fatigue life improvement of AISI 304L cruciform welded joints by cryogenic treatment", Eng. Fail. Anal., vol. 10, pp. 1-12, 2003.

[26] P. J. Singh, S. L. Mannan, T. Jayakumar and D. R. G. Achar, "Fatigue life extension of notches in AISI304L weldments using deep cryogenic treatment”, Eng. Fail. Anal., vol. 12, pp. 263-271, 2005.

[27] T. H. Myeong, Y. Yamabayashi, M. Shimojo and Y. Higo, "A new life extension method for high cycle fatigue using micromartensitic transformation on an austenitic stainless steel", Int. $J$. Fatigue, vol. 19(1), pp. S69-S73, 1997.

[28] T. Ianamura, R. Abe, T. H. Myeong, M. Shimojo and Y. Higo, "Fatigue life extension by nano-sized martensite particles in steels", in Proceedings of the 7th International Fatigue Congress, 1999, pp. 633-638.

[29] M. Shimojo and Y. Higo, "Formation of nanosized martensite and its application to fatigue strengthening", in Amorphous and Nanocristalline Materials - Preparation, Properties and Applications, eds. A. Inoue and K. Hashimoto, Berlin: Springer 2001, pp. 186204.

[30] J. Indumathi, J. Bijwe, A. K. Ghosh, M. Fahim and N. Krishnaraj, "Wear of cryo-treated engineering polymers and composites", Wear, vol. 225-229, pp. 343-353, 1999.

[31] H. H. Trieu, L. H. Morris, M. E. Kaufman, R. Hood and L. S. Jenkins, "Investigation of cryogenic treatment of UHMWPE", in Proceedings of the Sixteenth Southern Biomedical Engineering Conference, 1997, pp. 90-91.

[32] P. Chen, T. Malone, R. Bond and P. Torres, "Effects of cryogenic treatment on the residual stress and mechanical properties of an aerospace aluminum alloy", in Proceedings of the 4th Conference on Aerospace Materials, Processes, and Environmental Technology, 2001.

[33] K. E. Lulay, K. Khan and D. Chaaya, "The effect of cryogenic treatments on 7075 aluminum alloy", J. Mater. Eng. Perform., vol. 11(5), pp. 479-480, 2002.

[34] R. F. Barron, "Effect of cryogenic treatment on lathe tool wear", in Proceedings of the 13th International Congress of Refrigeration, vol. 1, 1973, pp. 529-534.

[35] R. F. Barron, "Do treatments at temperature below $-120^{\circ} \mathrm{F}$ help increase the wear resistance of tool steels? Here are some research findings that they do", Heat Treating, pp. 14-17, June 1974.

[36] R. F. Barron and C. R. Mulhern, "Cryogenic treatment of AISI-T8 and C1045 steels", Adv. Cryog. Eng. Materi., vol. 26, pp. 171-178, 1980.

[37] R. F. Barron, "Cryogenic treatment of metals to improve wear resistance", Cryogenics, vol. 22(8), pp. 409-313, 1982.

[38] R. F. Barron, "Cryogenic treatment of tool steels", in Proceedings of Conference Manufacturing Strategies, vol. 6, 1996, pp. 535-548.

[39] D. Mohan Lal, S. Renganarayanan and A. Kalanidhi, "Cryogenic treatment to augment wear resistance of tool and die steels", Cryogenics, vol. 41, pp. 149-155, 2001.

[40] K. P. Kollmer, "Applications \& Developments in the Cryogenic Processing of Materials", The Technology Interface, Electronic Journal for Engineering Technology, vol. 3(1), 1999. [Online] Available: http://et.nmsu.edu/ etti/ [Accessed Nov. 30, 2007].

[41] A. Bensely, D. Senthilkumar, D. Mohan Lal, G. Nagarajan, and A. Rajadurai, "Effect of cryogenic treatment on tensile behavior of case carburized steel-815M17", Mater. Charact., vol. 58, pp- 485491, 2007.

[42] G. Belisario, F. Caproni and E. Marchetti, "Influence of low temperature treatment on fatigue life of strain hardened steel specimen", in Proceedings of the Eleventh International Cryogenic Engineering Conference - ICEC 11, vol. D, 1986, pp. 791-794. 
[43] M. Pellizzari, A. Molinari, S. Gialanella and G. Straffelini, "Effetto del trattamento criogenico sulle proprietà microstrutturali dell'acciaio AISI H13", La Metallurgia Italiana, vol. 1, pp. 21-27, 2001.

[44] M. Pellizzari and A. Molinari, "Deep Cryogenic treatment of cold work tool steel", in Proceedings of 6th International Tooling Conference, vol. I, 2002, pp. 657-669.

[45] H. H. Liu, J. Wang, B. L. Shen, H. S. Yang, S. J. Gao SJ and S. J. Huang, "Effects of deep cryogenic treatment on property of
3Cr13Mo1V1.5 high chromium cast iron", Mater. Des., vol. 28, pp. 1059-1064, 2007.

[46] H. S. Yang, J. Wang, B. L. Shen, H. H. Liu, S. J. Gao and S. J. Huang, "Effect of cryogenic treatment on the matrix structure and abrasion resistance of white cast iron subjected to destabilization treatment", Wear, vol. 261, pp. 1150-1154, 2006.

[47] W. Zhisheng, S. Ping, L. Jinrui and H. Shengsun, "Effect of deep cryogenic treatment on electrode life and microstructure for spot welding hot dip galvanized steel", Mater. Des., vol. 24, pp. 687$692,2003$. 